\title{
PRELIMINARY REPORT ON GLACIER OBSERVATIONS IN NORDVESTFJORD, EAST GREENLAND
}

\author{
Ole B. Olesen and Niels Reeh
}

Introduction

In recent years great interest has developed concerning the balance of the Greenland ice sheet (Indlandsisen) and considerable efforts have been expended to throw light on the problem (for summary see Fristrup, 1966). Perhaps the greatest error in calculations is the estimation of the production of calf ice from the East Greenland glaciers for which, up til now, almost no accurate data has been available.

In connection with the GGU expedition to Scoresby Sund in JulyAugust, 1968, a glaciological programme was carried out by the authors. The main objects of the study were the measurement of frontal velocities and calf ice production in the three outlet glaciers in the innermost part of Nordvestfjord (approx. $72^{\circ} \mathrm{N}, 28^{\circ} \mathrm{W}$ ) : Daugaard-Jensen Gletscher, Charcot Gletscher, and Graah Gletscher.

At Daugaard-Jensen Gletscher observations were made during the periods July 20th - Aug. 2nd and Aug. 22nd - 25th. Work was carried out as follows:

1) Establishment of a base line for theodolite observations.

2) Surveying of characteristic points on the glacier surface once or twice a day in order to determine the position, height and flow velocity of the frontal part of the glacier.

3) Setting up of a $16 \mathrm{~mm}$ camera for time lapse photography of the front of the glacier. The camera worked for three weeks taking one frame every 15 minutes.

4) Observations and recordings of calvings.

Field work at Charcot Gletscher and Graah Gletscher was carried out in the period Aug. 3rd-9th, and consisted mainly of work of the type mentioned under points 1 and 2 above. 
Observations were also made on a small surging glacier in the Stauning Alper (approx. $71^{\circ} 35^{\prime} \mathrm{N}, 25^{\circ} 35^{\prime} \mathrm{W}$ ) which was visited in the period Aug. 10th-21st. A short study of ice velocity, surface collapse and moraine succession was undertaken.

Methods of observation

Theodolite measurements

The surface movement of the glaciers was measured by theodolite surveys from a base line on bedrock (A - B in fig. 5).

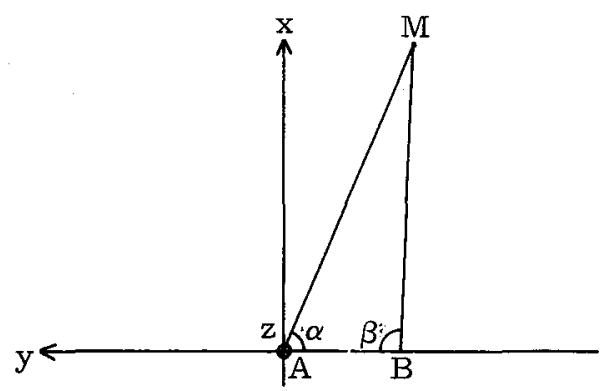

Fig. 5. Diagram showing basis for theodolite survey.

The measuring points on the glacier surface (point $M$ in fig. 5) were characteristic peaks, spots and other easily recognisable details, visible from both of the base line end-points. Once or twice a day the horizontal angles $\alpha$ and $\beta$ as well as the vertical angles were observed. The measurements were carried out with a Wild T2 one-second theodolite, using "changing face" point by point techniques and controlling the initial pointing at intervals.

The main problem with respect to the measurements was that for reasons of accuracy the base line $A B$ should have been of the order of 1 to $2 \mathrm{~km}$. In practice, even when employing a considerably shorter base line, the image in the theodolite telescope varied to such an extent when viewed 
from the two end-points that it was sometimes difficult to be certain of the identity of the measured point in question.

For this reason, as well as the practical problems involved in establishing and measuring a longer base line, the maximum base line length available in practice was some hundred metres. The lengths of the base lines used are given in table 3 .

A further problem with respect to the theodolite measurements was the change in shape, or even disappearance of ice peaks used as measuring points, due to ablation or collapse. The period of observation for some points was less than a day whereas for other points the time interval from the first observation to the last was up to 29 days.

\section{Precision of theodolite measurements}

The relative accuracy of the base line lengths is less than $0.5 \mathrm{o} / \mathrm{oo}$, introducing to coordinates and velocities a constant scale factor error of the same negligible order of magnitude.

Due to the difficulty of choosing distinct measuring points on the glacier surface, the precision of the angle measurement is somewhat less than the precision of the T2 theodolite. A final value for the standard deviation of the angle measurements cannot be given at present, but investigations carried out so far indicate a value near to $10^{\prime \prime}$.

\section{Time lapse photography}

The equipment used for the time lapse photography was somewhat primitive. The camera was an old Bolex equipped with a battery-powered motor for film transport and capable of shooting single frames. The camera was triggered by a timer (an electric clock) and a release system (trip coil). The motor and release system was powered by 10 Mallory $1.5 \mathrm{~V}$ alkaline batteries coupled in series, forming a $15 \mathrm{~V}$ battery of $10 \mathrm{Amp}$. hours capacity. All components were built into an aluminum box for protection against rain, snow and wind.

Probably due to a period of damp and cold weather and a minor miscalculation of the starting current of the motor, the batteries ran down after three weeks instead of the calculated six weeks working period. 
Analysis of observations

Theodolite measurements

Since the angle measurements were not carried out instantaneously at both points $A$ and $B$, a direct calculation of the coordinates of the measuring points is not possible (see fig. 5). The simplest way of making the coordinate calculation is to refer the angles to the same instant by linear interpolation between the observed values, and to perform the calculation using the interpolated values.

All the observations have been subjected to this operation, and coordinates ( $x, y$ and $z$ in fig. 5) and velocity components in the three directions have been calculated by means of an ALGOL III computer programme, elaborated (by the second author) for that purpose. The path lines of the measuring points obtained in this way are zigzag lines, showing large oscillations perpendicular to the main direction of movement. The altitudes of the measuring points also show some oscillation.

Considering the inaccuracies of the coordinates introduced by the observation errors, the zigzag lines become understandable. As an example consider point L1 (fig. 6). Using the estimated deviation error of observation of $10^{\prime \prime}$, the following errors of coordinates for this point are obtained:

$$
\begin{aligned}
& \mathrm{dx} \sim 1 \mathrm{~m} \\
& \mathrm{dy} \sim 0.5 \mathrm{~m} \\
& \mathrm{dz} \sim 0.15 \mathrm{~m}
\end{aligned}
$$

It may be appreciated that variations in the coordinates of up to 2 to 3 times these values may occur without being significant.

In order to separate real variations from variations due to measurement errors, an adjustment of the observations is necessary. These calculations are in hand and no final results can yet be given. The procedure to be applied is the following:

The angle variations with respect to time are adjusted by regression analysis, and the best fitting curve determined by least squares. On the basis of this analysis the most likely path line of the measuring point is determined and confidence limits for coordinates and velocities are calculated, giving a background for deciding whether variations in these quantities are significant. 
Analysis of films and photographs

To date films and photographs have been used only for two purposes : recording glacier calvings, and determining frontal glacier heights in cases where theodolite observations have shown to be inaccurate.

Since the altitude of the site of the photographs and the angle between the camera axis and the horizontal level are known it is possible to convert measurements made on the photographs into actual distances. In most cases the angle between the camera axis and the horizontal level is known within $1-2^{\circ}$, assuring a relative accuracy of less than $5 \%$. Comparisons of front-heights obtained from photographs and front-heights obtained by accurate theodolite measurements are in very good agreement.

$$
\text { Provisional results }
$$

All velocity data given below are provisional values calculated as mean values over the period of observation for the point in question. More detailed data will appear in a later report.

\section{Daugaard-Jensen Gletscher}

It appears that, as shown in fig. 6, the glacier front has retreated about $1.5 \mathrm{~km}$ from the position on aerial photographs taken in 1952. However, compared to the variations in frontal position during the period of observation in 1968 this recession cannot be considered significant.

The elevations of the glacier surface with respect to sea level are indicated in fig. 7, illustrated by one cross-section and 2 longitudinal sections of the glacier. The lines of these sections are shown in fig. 6 .

The altitudes of the glacier surface given in fig. 3 should be taken with some reservation since the surface of the glacier is extremely crevassed and uneven and height variations of $10-20 \mathrm{~m}$ are common within very short distances. However, since the measuring points were in most cases ice peaks rising similar distances from the surface, the profile shape may be considered reliable. 


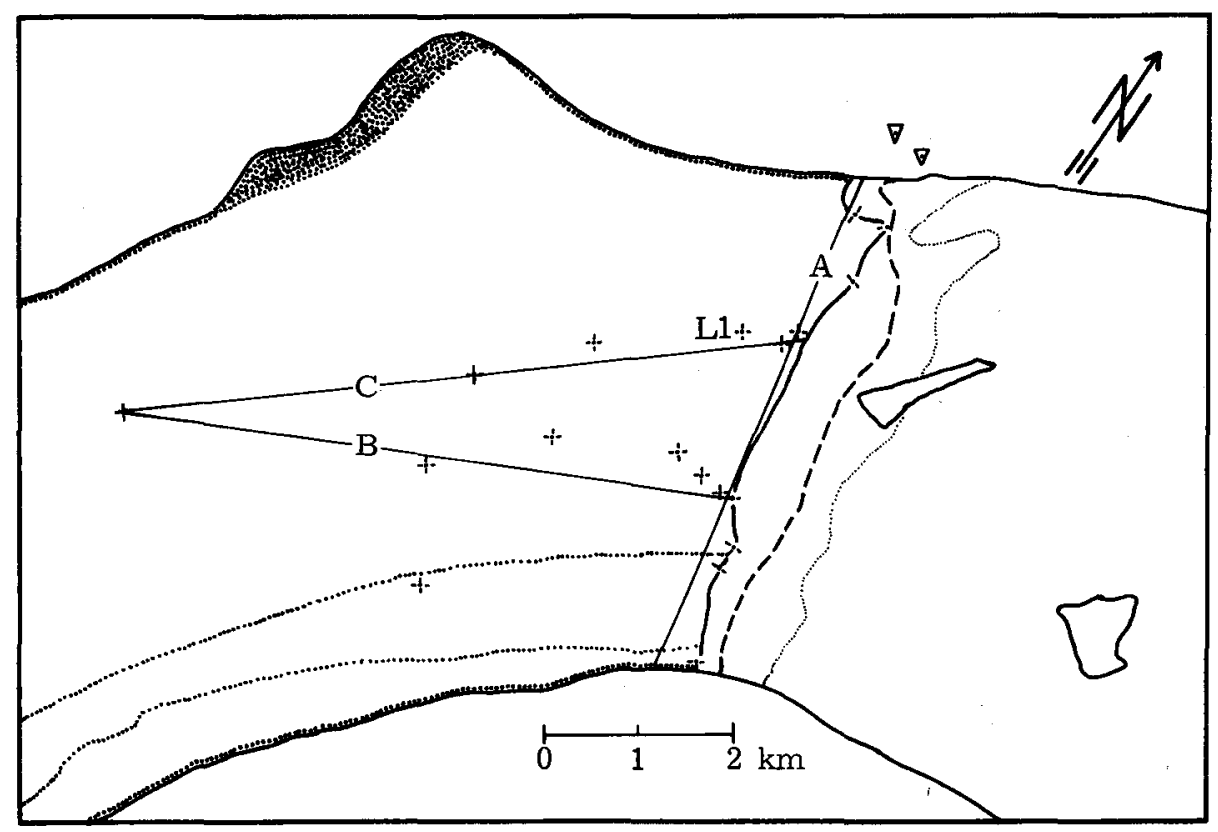

Fig. 6. Map of frontal part of Daugaard-Jensen Gletscher. Redrawn after Geodætisk Institut 1:200000 sheet $71 \varnothing 3$............... Front 1952 . _- Front before calving. _ Front after calving. $\nabla$ Base point. - Points measured.

Apart from the northern marginal zone of the glacier which is comparatively low, the level of the northern part of the glacier is almost constant at 70-80 $\mathrm{m}$ above sea level. There appears to be a depression situated at a distance of about 2 to $2.5 \mathrm{~km}$ behind the front (see northern longitudinal section) and this may indicate that the northern part of the glacier is afloat. The southern part of the glacier exhibits an even surface inclination in the direction of movement, has somewhat greater frontheights and is quite probably grounded.

The variation of surface velocity along the line of the sections shown in fig. 7 is presented in fig. 8. 


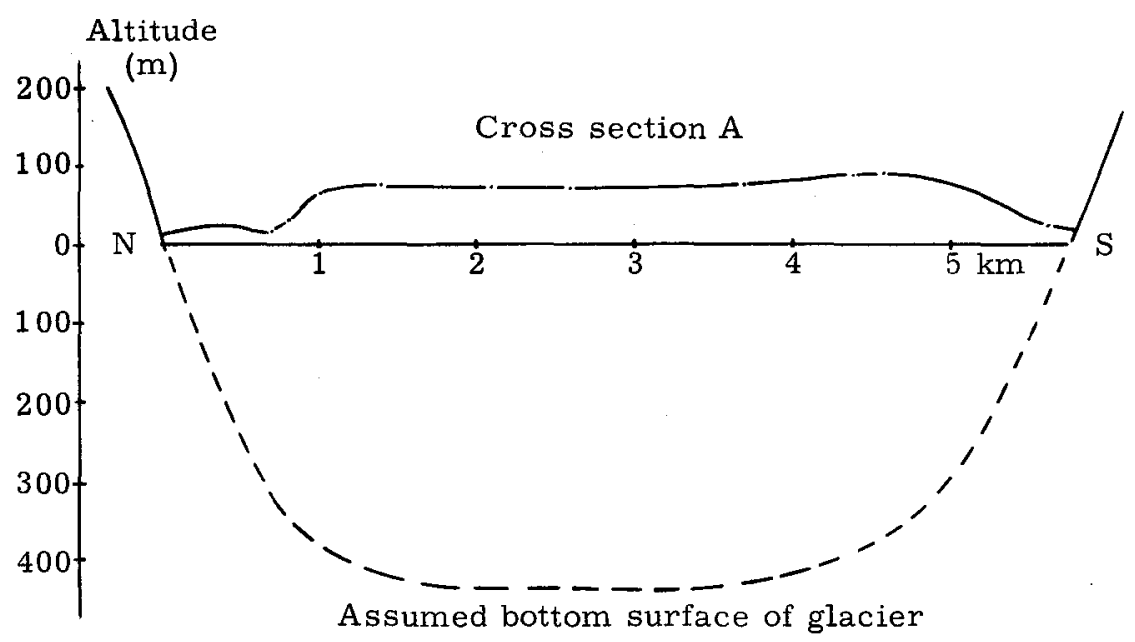

Altitude
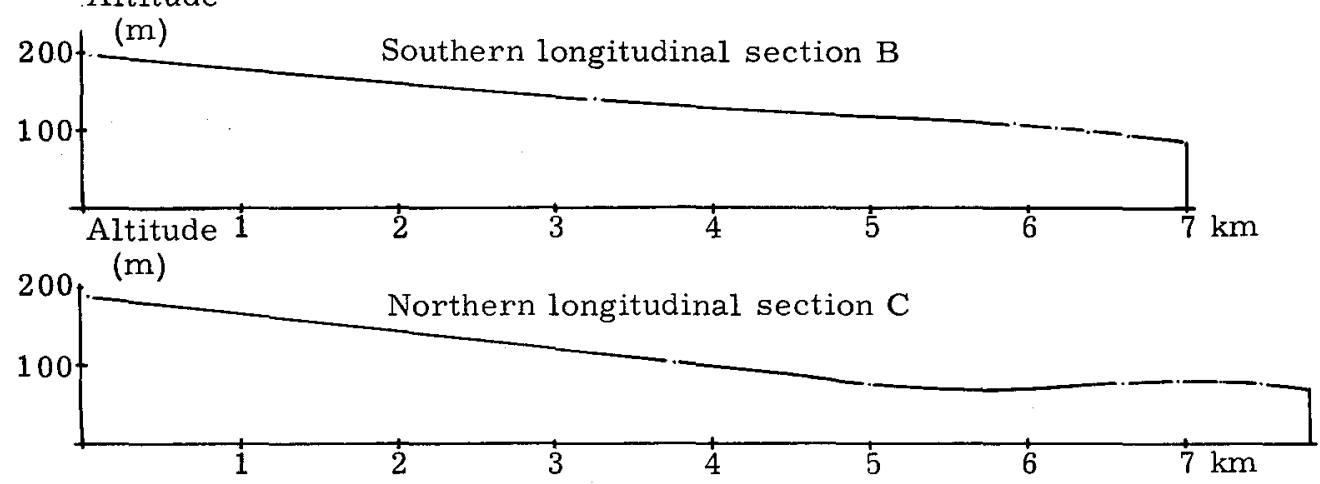

Fig. 7. Cross-section and longitudinal sections of Daugaard-Jensen Gletscher.

The cross-sectional velocity profile indicates that the velocity is nearly constant across the central section of the glacier with large velocity differences within narrow zones along the glacier margins. The observed velocities vary between $12.3 \mathrm{~m} / 24 \mathrm{~h}$ and $8.0 \mathrm{~m} / 24 \mathrm{~h}$; the mean velocity is $10.2 \mathrm{~m} / 24 \mathrm{~h}$. The fact that the velocity maximum is situated to the north of the midpoint of the glacier supports the conclusion concerning floating conditions deduced from the surface elevations. 

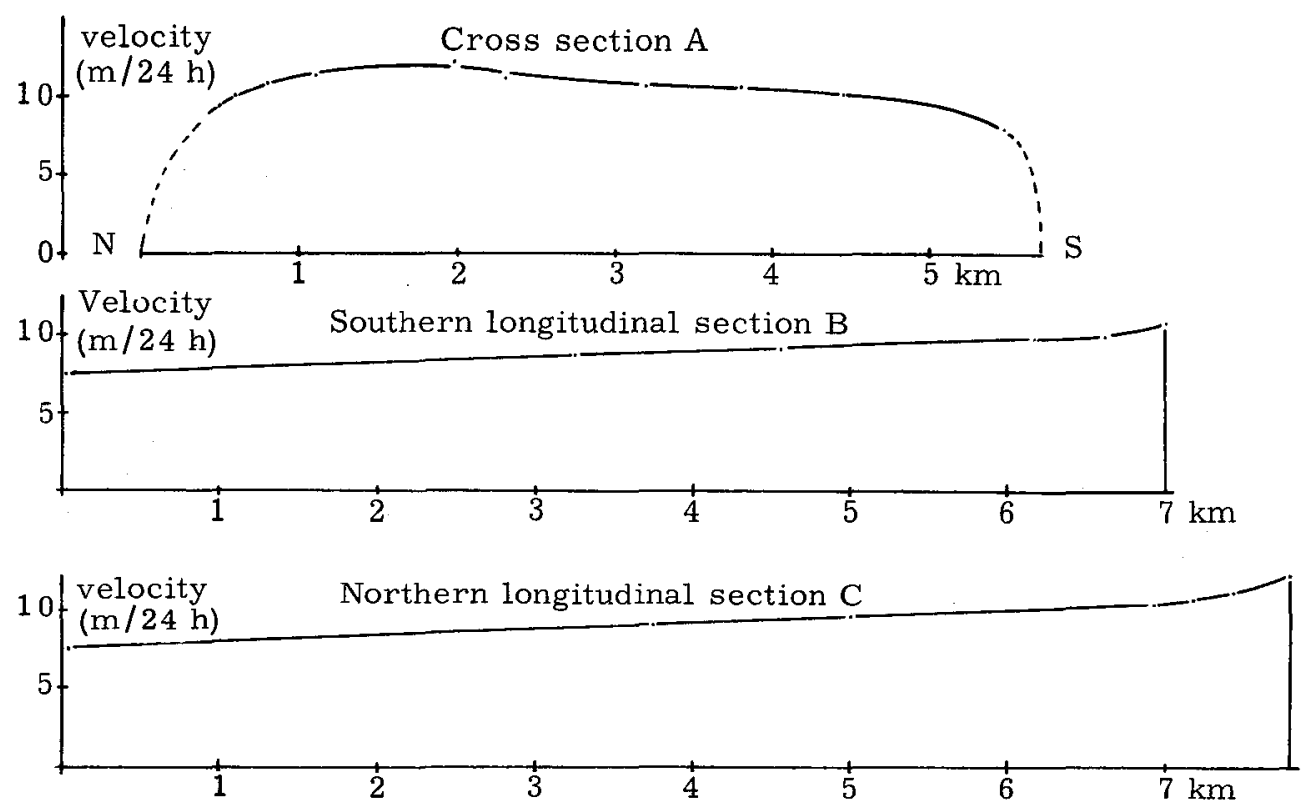

Fig. 8. Surface velocities of Daugaard-Jensen Gletscher.

In the longitudinal sections the velocity increases in the direction of movement from $7.4 \mathrm{~m} / 24 \mathrm{~h}$ at a distance of about $7.5 \mathrm{~km}$ behind the front to $12.3 \mathrm{~m} / 24 \mathrm{~h}$ at the front. The variation is nearly linear as far forward as a point situated about $1 \mathrm{~km}$ behind the front; from this point on the velocity increases rapidly. It is interesting to note that the point where the rapid velocity increase commences coincides with the site of a major crevasse between the main glacier and the part of the glacier which became detached during the principal calving described below.

Production of calf ice

The width of the glacier front is $5.7 \mathrm{~km}$. From the height of the front and observations of calvings the mean thickness of the glacier is estimated as $500 \mathrm{~m}$. On the basis of these figures and the velocity observations the production of calf ice is estimated to about $10 \mathrm{~km}^{3} /$ year.

During the period of observation four major calvings were noted. Table 2 indicates the date of calvings and the approximate amount of ice detached. 
Table 2

\begin{tabular}{cccc} 
& Date & \multicolumn{1}{c}{ Place } & Amount of ice detached $\left(\mathrm{km}^{3}\right)$ \\
1 & $22-7$ & Northern part of front & 0.15 \\
2 & $24-7$ & Southern part of front & 0.1 \\
3 & $23-8$ & Central part of front & 1.2 \\
4 & $25-8$ & Northern part of front & 0.15
\end{tabular}

In addition to the four major calvings listed $3-4$ minor calvings each of 5-25 million $\mathrm{m}^{3}$ were recorded. Smaller calvings from the upper part of the front were often observed.

Although the front was not observed in the period Aug. 2nd-22nd apart from a short visit on Aug. 10th it can be stated that no major calving took place during this period. An examination- of the time lapse photos of the front shows that until Aug. 13th, when the camera stopped, no major calving had taken place. In the remaining period, Aug. 13th-22nd, a comparison between the last frame of the time lapse film and photographs taken on the arrival at the front on Aug. 22nd shows that no major calving had taken place.

Observations indicate a certain order of events in the calving procedure. This may be inferred from the fact that the shape of the front and the position and shape of the icebergs in front of the glacier were similar at the arrival on the site on July 20 th and after the major calving of Aug. 25th; comparable positions of icebergs and shape of front are also apparent on aerial photographs taken on Aug. 13th 1952 and July 16 th 1961 . The first and the last of the major calvings (see Table 2), may be considered to correspond to the same stage in the course of calving, indicating a 5 week periodicity. The periodicity can also be calculated from the amount of calf ice produced in a given time and the frontal velocity of the glacier; a periodicity of 9 weeks is thus obtained. Judging from these figures, 6 to 10 major calvings probably occur during a year.

The order of events in the calving procedure indicated by the 1968 observations is as follows: 
1. Advance of the front during a period of about a month during which no calving activity of importance takes place. Due to the greater velocities in the central part of the glacier the front assumes a curved convex shape (the broken line in fig. 6).

2. Calving of the central advanced part of the front over a width of approximately $5 \mathrm{~km}$. At this calving an amount of ice of the order of 1.1 to $1.5 \mathrm{~km}^{3}$ becomes detached from the front, leading to the formation of two very large icebergs (0.19 and $0.14 \mathrm{~km}^{3}$ each) which float away with the old glacier surface in an upright position, and several other large and small icebergs which rotated and broke up upon calving.

3. Shortly afterwards (a matter of days) there occurs the calving of marginal parts of the glacier, which owing to the major calving of the central part are now the most advanced parts of the front (the dotted line in fig. 6). The amount of ice detached at each of these calvings is of the order of $0.1 \mathrm{~km}^{3}$.

With respect to all the major calvings observed, the formation of a major crevasse is characteristic. It forms at the surface of the glacier approximately parallel to the front along a line separating the ice shortly to be detached from the remaining part of the glacier. The crevasse opens progressively, and in the stages immediately prior to calving extends from the upper surface of the glacier to probably below sea level to judge from the observed width of the crevasse at the glacier surface and at sea level respectively.

The preliminary results of the calculation of movements and velocities indicate high velocities in the part of the glacier in front of the crevasse and some differential movement across the crevasse, but at present nothing can be said with certainty since the corrections of the observations have not yet been carried out and much film and photographic material remains to be analysed.

\section{Iceberg behaviour}

On detachment from the glacier front the large icebergs behave in different ways. At the first major calving the iceberg tilted backwards and the frontal part of the berg rose out of the water. The second calving was not observed, but as regards the third, two icebergs floated away in the same position as they had assumed as a part of the glacier, while 
other icebergs turned completely over, some forwards and others backwards. At the fourth major calving the iceberg tilted forwards.

\section{Charcot Gletscher and Graah Gletscher}

As both glaciers were observed from a height of approx. $1700 \mathrm{~m}$, at distances of 2 to $5 \mathrm{~km}$ and with relatively short base lines, the measurements have a degree of uncertainty. However, by presuming a direction of flow and using the increments of the measured angles for each point, fairly reliable results have been obtained; the possible error is estimated to be of the order of $10 \%$.

In comparison to aerial photographs from 1950 the glacier fronts have been very stable. Only Charcot Gletscher has receeded, about $600 \mathrm{~m}$; this is not considered to be a significant amount.

The variation of the surface velocity along cross-sections at the fronts of the two glaciers is shown in fig. 9.

Further results are given in table 3 which also summarises the results from Daugaard-Jensen Gletscher.
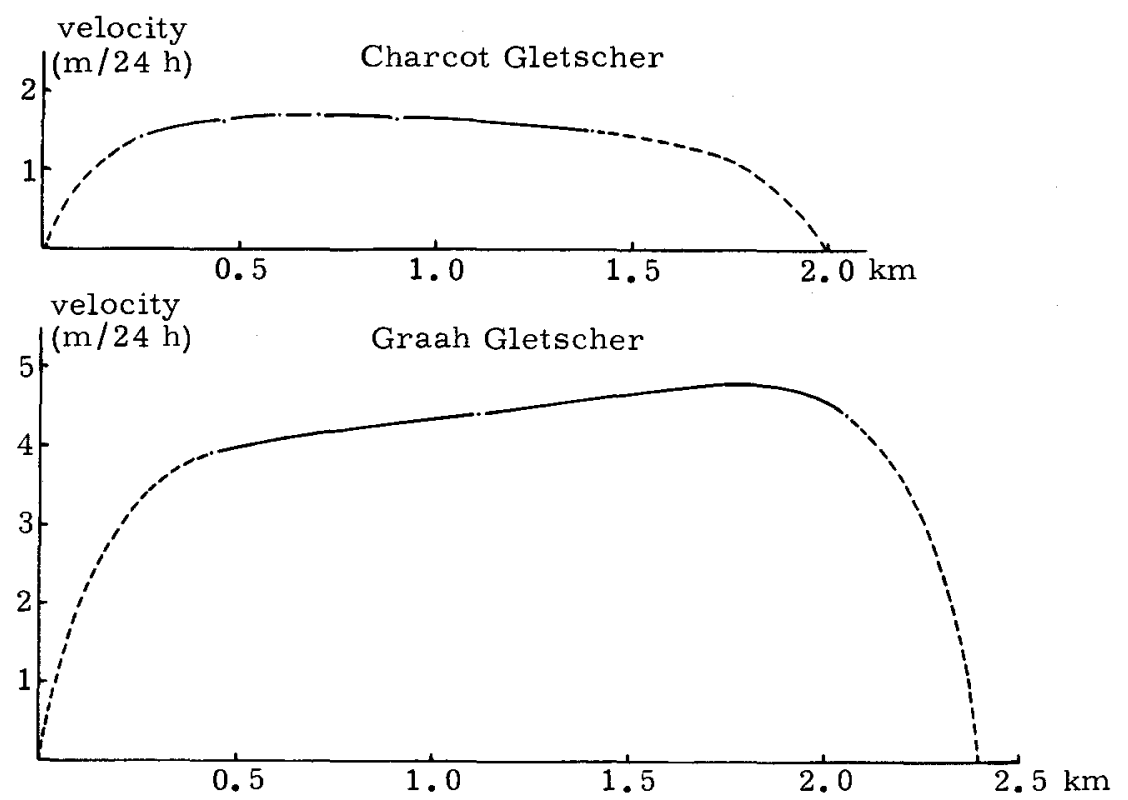

Fig. 9. Surface velocities of Charcot Gletcher and Graah Gletcher. 
Table 3

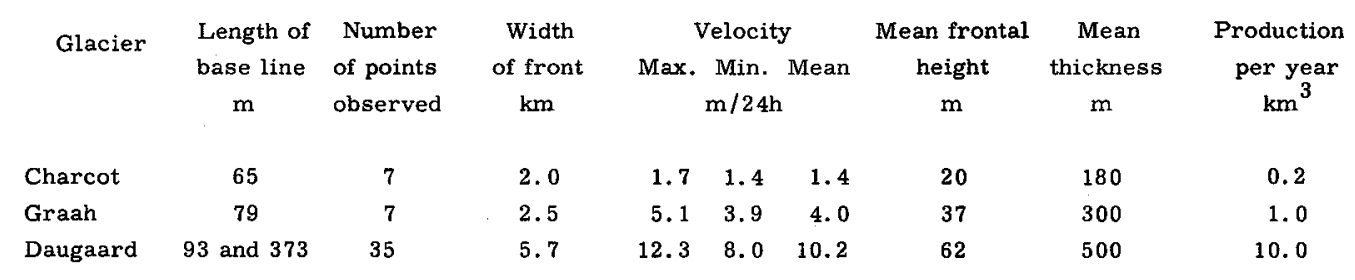

The surging glacier in the Stauning Alper

The surging glacier in the Stauning Alper was discovered by Henriksen and Watt (1968, p. 77) on a reconnaissance expedition to Nordvestfjord in 1967. Aerial photographs from 1947 and 1950 show the glacier to have been stationary, while in 1961 the glacier had advanced $3 \mathrm{~km}$. In 1967 the glacier terminated in Nordvestfjord, that is to say $7.5 \mathrm{~km}$ in advance of its 1950 position, and had begun to collapse.

During the visit to the glacier in 1968 two cross profiles were measured by theodolite and by hard level respectively in order to estimate the volume loss due to surface collapse.

The age of lichens on ancient side moraines indicate that an earlier advance took place 150-250 years B.P.

The area of land around the Stauning Alper is covered by aerial photographs taken in the years 1933,1947,1950,1961 and 1968 and a search for more advancing glaciers is in progress. At the time of writing two more advancing glaciers have been discovered in different parts of the Stauning Alper.

\section{Conclusions}

The most interesting result of the investigations is the unexpectedly low calf ice production ( $10 \mathrm{~km}^{3} /$ year) from Daugaard-Jensen Gletscher. This production is of the same order of magnitude as that of the glaciers Sermeq kujatdleq, Store Qarajaq Gletscher and Rinks Isbræ (Carbonnell and Bauer, 1968) in West Greenland. Although Daugaard-Jensen Gletscher 
belongs to the group of very productive glaciers, it is far from being comparable to Jakobshavn Isbræ which has a calf ice production of approximately $30 \mathrm{~km}^{3}$ /year (Carbonnell and Bauer, 1968).

Another feature to be emphasised is the apparent periodicity in the calving procedure of Daugaard-Jensen Gletscher. Observations over long periods of other Greenland glacier fronts could reveal whether this is a common phenomenon.

\section{References}

Carbonnell, M. and Bauer, A. (1968) Exploitation des couvertures photographiques aériennes répétées du front des glaciers velânt dans Disko Bugt et Umanak Fjord, juin - juillet 1964. Meddr Grфnland, Bd. 173, Nr. 5.

Fristrup, B. (1966) The Greenland Icecap. Copenhagen: Rhodes Intern. Sci. Publ.

Henriksen, N. and Watt, W.S. (1968) Geological reconnaissance of the Scoresby Sund fjord complex. Rapp. Grфnlands geol. Unders. , Nr. 15, $72-77$. 